\title{
Expression of heat-shock proteins in Streptococcus pyogenes and their immunoreactivity with sera from patients with streptococcal diseases
}

\author{
J. A. C. LEMOS, M. GIAMBIAGI-DEMARVAL and ANGELA C. D. CASTRO
}

Medical Microbiology Department, Microbiology Institute, CCS, Federal University of Rio de Janeiro, 21491590, Rio de Janeiro, RJ, Brazil

\begin{abstract}
The heat-shock response of Streptococcus pyogenes following exposure to elevated growth temperatures, and the immunological reactivity of heat-shock proteins (HSPs) in streptococcal infections were studied. Two major proteins of 65 and $75 \mathrm{kDa}$ were expressed when a $S$. pyogenes strain was shifted from $37^{\circ} \mathrm{C}$ to heat-shock temperatures of 40,42 and $45^{\circ} \mathrm{C}$. Such proteins are members of the GroEL and DnaK families recognised in a Western blot assay with polyclonal antibodies against Escherichia coli GroEL and $E$. coli DnaK, respectively. Two-dimensional autoradiograms of polypeptides labelled at 37 or $42^{\circ} \mathrm{C}$ showed an increased intensity of three spots at $42^{\circ} \mathrm{C}$. A monoclonal antibody (MAb) against HSP 63 of Bordetella pertussis also recognised the 65-kDa inducible protein, although MAbs against Mycobacterium tuberculosis HSP 65 failed to recognise this protein. Immunoblot analysis of sera from individuals with rheumatic fever or uncomplicated streptococcal diseases revealed seven major immunogenic protein bands, two of which also reacted with anti- $E$. coli GroEL and DnaK polyclonal antibodies. Furthermore, antibodies to the GroEL and DnaK proteins were also detected in sera from patients with either rheumatoid arthritis or systemic lupus erythematosus. These results demonstrated a heat-shock response of $S$. pyogenes, and indicated the presence of an immune response against HSPs in streptococcal diseases.
\end{abstract}

\section{Introduction}

Streptococcus pyogenes (Lancefield group A Streptococcus) is an important human pathogen causing various infections from mild sore throat to fatal toxic shock-like syndrome; and may also be involved in nonsuppurative sequelae (e.g., rheumatic fever, RF). Since the mid-1980s, particularly in the USA and Europe, there has been an increasing resurgence of severe group A streptococcal diseases [1].

Heat-shock proteins (HSPs) or stress proteins are a family of proteins whose synthesis is induced or accelerated when cells are exposed to sublethal heat shock or to various other stress factors. HSPs are ubiquitous in nature and are grouped according to their apparent mol.wt. They represent a group of proteins with a highly conserved structure [2]. HSPs have been implicated in the pathogenesis of several autoimmune diseases, including rheumatoid arthritis (RA) [3]. One of the major symptoms in the

Received 6 Nov. 1997; accepted 9 Dec. 1997.

Corresponding author: Dr A. C. D. Castro. pathogenesis of RF is arthritis and it is possible that RA and RF may be similar in their pathogenic pathways. However, few reports are available that correlate HSPs with streptococci [4-8] and to our knowledge this is the first characterisation of this group of proteins in $S$. pyogenes.

The heat-shock response in one strain of $S$. pyogenes $(145 / 93)$ is reported, in addition to the identification of two HSP homologues to Escherichia coli DnaK and GroEL, based upon immunological reactivity, mol.wt and induction by heat shock. Furthermore, this study examined the reaction of $S$. pyogenes protein homologues to GroEL and DnaK with human immune sera from patients with RF, mild streptococcal diseases (MSD), RA and systemic lupus erythematosus (SLE).

\section{Materials and methods}

Bacterial strains and culture conditions

S. pyogenes (145/93), M non-typable, isolated from blood culture was used for the HSP induction studies 
and Western blot analysis. Whole-cell proteins of strains of $E$. coli (ATCC 2592), Mycobacterium tuberculosis (1850) and Bordetella pertussis (165) belonging to our laboratory collection were used as positive controls, with monoclonal and polyclonal antibodies against HSPs and also with the human sera described below. The strains were cultivated in Brain Heart Infusion Broth (BHI; Difco) overnight at $37^{\circ} \mathrm{C}$, except for $M$. tuberculosis which was grown in Middlebrook $7 \mathrm{H} 9$ medium for 2 weeks at $37^{\circ} \mathrm{C}$.

\section{Human sera}

Human sera collected from patients with RF (12 patients), MSD (6), SLE (4) and RA (4) were also used in a Western blot assay (diluted 1 in 100). Eight sera from healthy individuals (anti-streptolysin $0<125 \mathrm{IU} / \mathrm{ml}$ ) were included as controls.

\section{Isotopic labelling and bacterial proteins analysis}

Overnight cultures were diluted in BHI to $10^{7} \mathrm{cfu} / \mathrm{ml}$ and incubated for $30 \mathrm{~min}$ at $37^{\circ} \mathrm{C}$. Cells were harvested by centrifugation at $5000 \mathrm{~g}$ for $10 \mathrm{~min}$ and resuspended to $10^{8} \mathrm{cfu} / \mathrm{ml}$ in a methionine-free essential medium (Gibco) with ${ }^{35} \mathrm{~S}$-methionine (Amersham) $100 \mu \mathrm{Ci} / \mathrm{ml}$. Portions of these cultures were heat-shocked (40, 42 and $45^{\circ} \mathrm{C}$ ) for $30 \mathrm{~min}$ whilst controls were left at $37^{\circ} \mathrm{C}$. Cells were collected by centrifugation at $5000 \mathrm{~g}$ for $10 \mathrm{~min}$, washed in $\mathrm{NaCl} 0.85 \% \mathrm{w} / \mathrm{v}$ and incubated at $37^{\circ} \mathrm{C}$ for $2 \mathrm{~h}$ with lysozyme (Sigma) $10 \mathrm{mg} / \mathrm{ml}$ and mutanolysin (Sigma) $500 \mathrm{U} / \mathrm{ml}$.

\section{$S D S-P A G E$}

Cells were lysed by boiling in one volume of sample buffer $(0.5 \mathrm{M}$ Tris, SDS $4 \% \mathrm{w} / \mathrm{v}, \beta$-mercaptoethanol $10 \% \mathrm{v} / \mathrm{v}$, glycerol $20 \% \mathrm{v} / \mathrm{v}$, bromophenol blue $0.1 \% \mathrm{v} / \mathrm{v}$ ). Cellular extracts containing $10^{5} \mathrm{cpm}$, from each set of samples, were loaded on to each gel as described by Ausubel et al. [9]. Gels were exposed to X-ray film (X-OMAT, Kodak) and processed with MC110 developer (Kodak) and fixed (X Dental, Kodak).

\section{Two-dimensional gel electrophoresis}

Cells were precipitated with TCA $10 \% \mathrm{w} / \mathrm{v}$, washed once in ice-cold absolute ethanol and once in chloroform:methanol (1:1). After centrifugation at $5000 \mathrm{~g}$ for $10 \mathrm{~min}$, cells were resuspended in lysis buffer comprising $9.5 \mathrm{M}$ urea (Gibco); nonidet P-40 v (LKB Pharmacia) $2 \% \mathrm{v} / \mathrm{v}$; ampholytes $\mathrm{pH}$ gradient 5-8 (LKB Pharmacia) $1.6 \% ; 0.4 \%$ ampholytes $\mathrm{pH}$ gradient $3.5-$ 10 (LKB Pharmacia) $0.4 \% ; \beta$-mercaptoethanol $5 \% \mathrm{v} / \mathrm{v}$. Two-dimensional electrophoresis was performed as described previously [9]. The isoelectricfocusing (IEF) gels were pre-run for $30 \mathrm{~min}$ each at 200,300 and $400 \mathrm{~V}$. Cellular extracts, containing $10^{6} \mathrm{cpm}$ from each set of samples were loaded on to each gel, electrophoresed for $16 \mathrm{~h}$ at $400 \mathrm{~V}$ and for an additional $2 \mathrm{~h}$ at $800 \mathrm{~V}$. A polyacrylamide $10 \%$ gel was used for the second dimension. Radioactive gels were exposed to X-ray film and processed as described above.

\section{Western blot analysis}

Whole-cell proteins separated by SDS-PAGE with $10 \%$ gels were transferred on to nitrocellulose membranes (Immobilon-P, Millipore) as described previously [9]. After electrophoretic transfer, membranes were blocked with TBS buffer (20 mM Tris, $137 \mathrm{mM} \mathrm{NaCl}, \mathrm{pH} \mathrm{7.6)}$ with skimmed milk $4 \% \mathrm{w} / \mathrm{v}$ and Tween $200.1 \% \mathrm{v} / \mathrm{v}$. After blocking, membranes were incubated with $E$. coli anti-GroEL or anti-DnaK polyclonal antibodies or with anti-HSP $63 \mathrm{~B}$. pertussis (54G8) and anti-HSP $65 \mathrm{M}$. tuberculosis monoclonal antibodies (MAbs: IT-13, IT56 and IT-64) or with human sera for $1 \mathrm{~h}$ at room temperature. After three washes in the blocking buffer the membranes were incubated for $1 \mathrm{~h}$ with peroxidaseconjugated secondary antibodies. Bound antibodies were detected by the ECL system (Amersham) with MAbs and by 3.3 diaminobenzydine (Sigma) $0.5 \mathrm{mg} /$ $\mathrm{ml}$ in TBS with polyclonal antibodies and human sera. Antisera were diluted 1 in 1000 in TBS buffer with the exception of the antibodies against $M$. tuberculosis (1 in 100).

\section{Results}

Cultures of $S$. pyogenes that were heat shocked from $37^{\circ} \mathrm{C}$ to higher temperatures $\left(40,42\right.$ and $\left.45^{\circ} \mathrm{C}\right)$ showed a progressive increase in the synthesis of two proteins (65 and $75 \mathrm{kDa}$ ) (Fig. 1). A $40 \%$ reduction of wholecell protein synthesis at $45^{\circ} \mathrm{C}$ was demonstrated by radiolabelled counts. Two-dimensional autoradiograms of polypeptides labelled at $37^{\circ} \mathrm{C}$ or $42^{\circ} \mathrm{C}$ showed an increase in the intensity of three spots at $42^{\circ} \mathrm{C}$ with apparent molecular masses of 82,75 and $65 \mathrm{kDa}$ and with estimated isoelectric points of $6.5,5.5$ and 5.3, respectively (Fig. 2).

Western-blot analysis with E. coli anti-GroEL (Fig. 3a) and anti-DnaK (Fig. 3b) polyclonal antibodies revealed bands at 65 and $75 \mathrm{kDa}$, respectively, in heatshocked $\left(40\right.$ and $\left.42^{\circ} \mathrm{C}\right)$ and control cells $\left(37^{\circ} \mathrm{C}\right)$ of $S$. pyogenes. These bands were identical to the major bands found in the autoradiograms. The $65-\mathrm{kDa}$ heatinduced protein was also recognised by a MAb produced against a $63-\mathrm{kDa}$ HSP of $B$. pertussis and did not react with the three MAbs against HSP 65 of $M$. tuberculosis (data not shown). Immunoblot analysis of the proteins subjected to two-dimensional electrophoresis showed only one spot that was immunologically related to each antibody, indicating only one isoform to each of the protein families (data not shown). Seven major streptococcal proteins $(75,65$, $54,48,46,38$ and $29 \mathrm{kDa}$ ) were detected by Western blot assays with 18 human sera from individuals with RF or MSD (Fig. 4). Differences in band patterns 


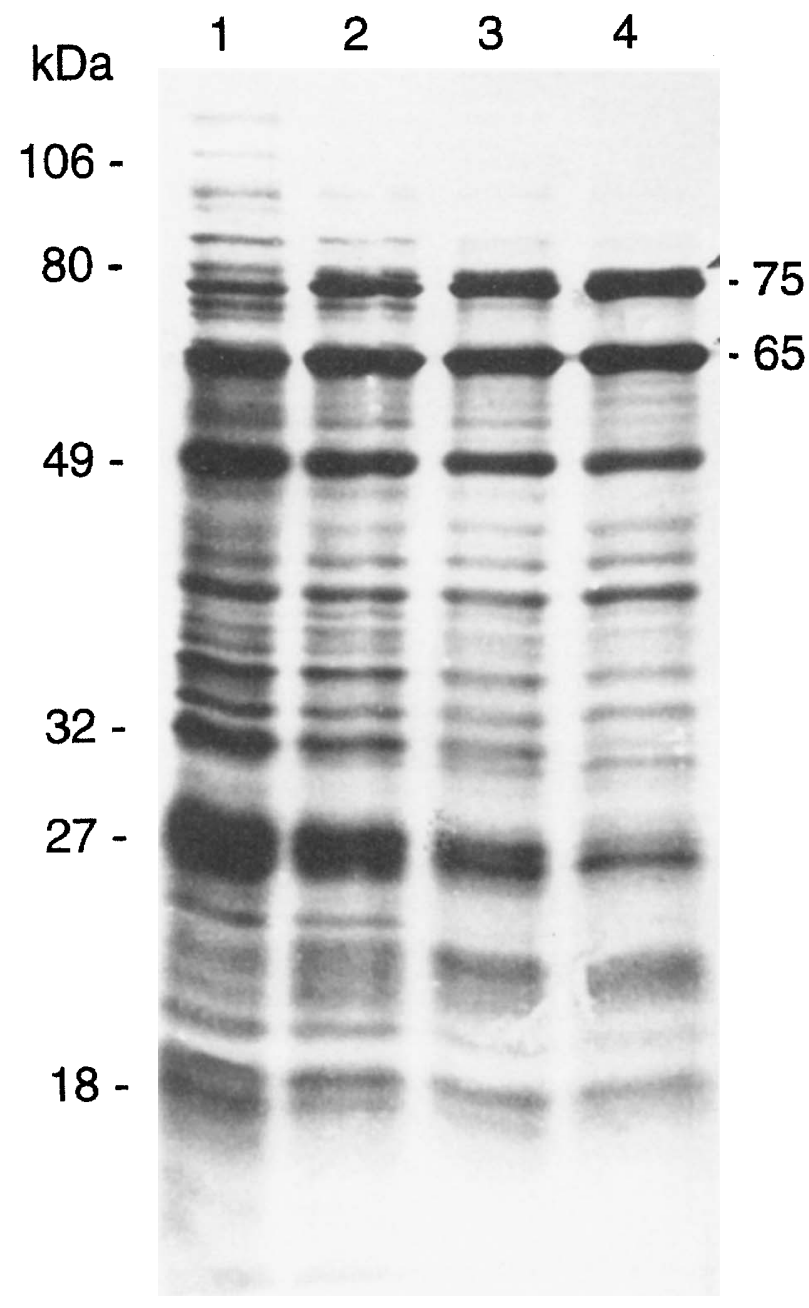

Fig. 1. Autoradiograms of $\left[{ }^{35} \mathrm{~S}\right]$ methionine-labelled proteins of $S$. pyogenes $(145 / 93)$ under non-heat-shocked and heat-shocked conditions for $30 \mathrm{~min}$. Total cell proteins of $S$. pyogenes at: $1,37^{\circ} \mathrm{C} ; 2,40^{\circ} \mathrm{C} ; 3,42^{\circ} \mathrm{C}$; $4,45^{\circ} \mathrm{C}$, were separated on SDS-PAGE $10 \%$ gels; $10^{5}$ $\mathrm{cpm}$ were loaded on to each lane. Arrows indicate the position of the heat-shock proteins, and mol.wt standards are indicated on the left in $\mathrm{kDa}$.

were not observed between the RF and MSD sera. The $75-$ and $65-\mathrm{kDa}$ protein bands corresponded in molecular mass to the $S$. pyogenes DnaK and GroEL homologues. Furthermore, human sera from individuals with RA (four) and SLE (four) reacted with whole-cell proteins from S. pyogenes whether or not these cultures had been subjected to heat shock and failed to react with whole-cell proteins from $E$. coli and $M$. tuberculosis. Also, the $75-$ and $65-\mathrm{kDa}$ heatinduced proteins of $S$. pyogenes reacted with the RF, RA and SLE sera (Fig. 5). In all cases, the reactivity of immune sera tested against heat-shocked and nonheat-shocked preparations appeared to be more prominent in heat-shocked preparations. None of the eight normal human sera tested showed any significant reactivity against the $S$. pyogenes proteins (one of these sera is shown in lane 5 of Fig. 4). a
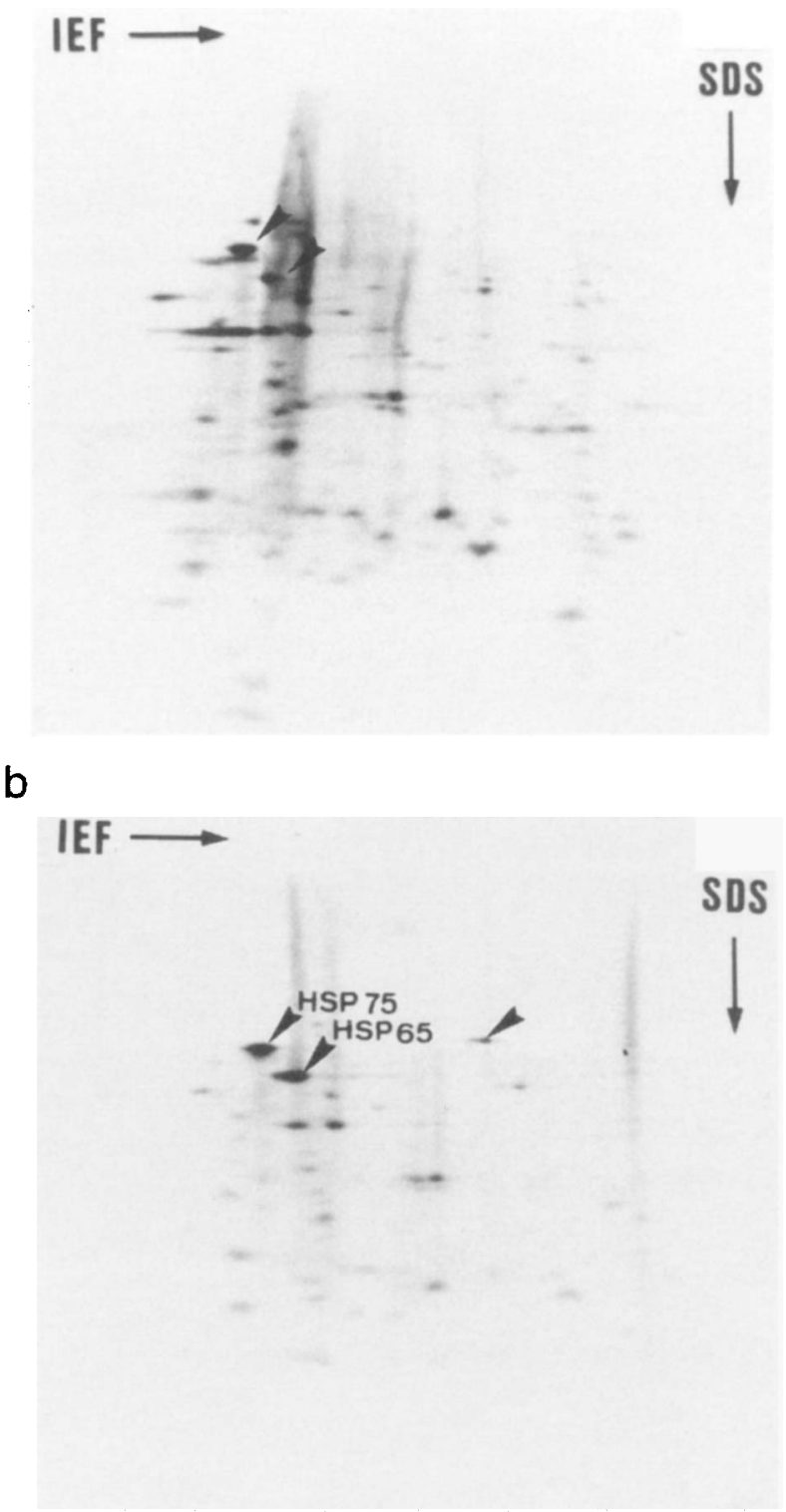

Fig. 2. Two-dimensional autoradiograms of $\left[{ }^{35}\right.$ S $]$ methionine-labelled proteins of $S$. pyogenes $(145 / 93)$ at: a, $37^{\circ} \mathrm{C}, \mathrm{b}, 42^{\circ} \mathrm{C}$, for $30 \mathrm{~min} ; 10^{6} \mathrm{cpm}$ were loaded on to each gel. Total cell proteins were separated by IEF in the first dimension $(\mathrm{pH} \mathrm{5-8)}$ and by SDS-PAGE in $10 \%$ gels in the second dimension. Arrows indicate heat-inducible proteins.

\section{Discussion}

Despite current knowledge concerning the autoimmune response in RF [10] and the possible role of HSPs in autoimmune diseases [3], the heat-shock response has not been characterised in $S$. pyogenes to date. The present study demonstrated that $S$. pyogenes exhibited a heat-shock response when exposed to high growth temperatures by a decrease in general protein synthesis and an increase of two protein bands ( 75 and $65 \mathrm{kDa}$ ), which belong to the DnaK and GroEL families, respectively. In concordance with these results, Jayaraman and Burne [7] observed two heat-inducible protein 
a

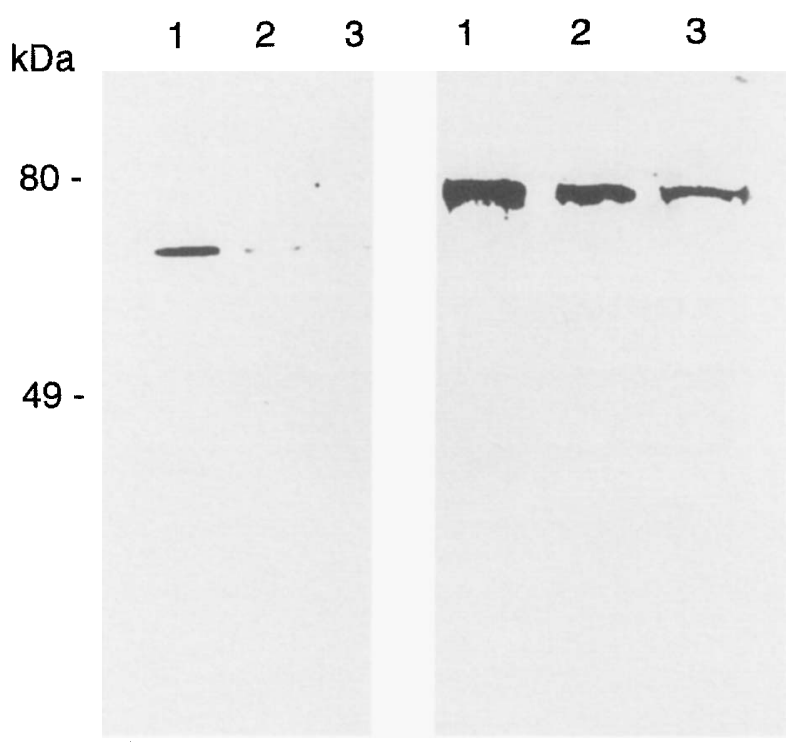

Fig. 3. Identification of GroEL and DnaK homologues in solubilised cellular extracts of $S$. pyogenes by Western blot. Proteins from unstressed cells and heat-shocked cells of strain $145 / 93$ were probed with polyclonal antibodies against (a) GroEL, (b) DnaK. Lanes contain proteins from heat-shocked cells at (1) $45^{\circ} \mathrm{C}$ or $(2) 42^{\circ} \mathrm{C}$ and control cells maintained at $(3) 37^{\circ} \mathrm{C}$. Mol.wt standards are indicated on the left in $\mathrm{kDa}$.

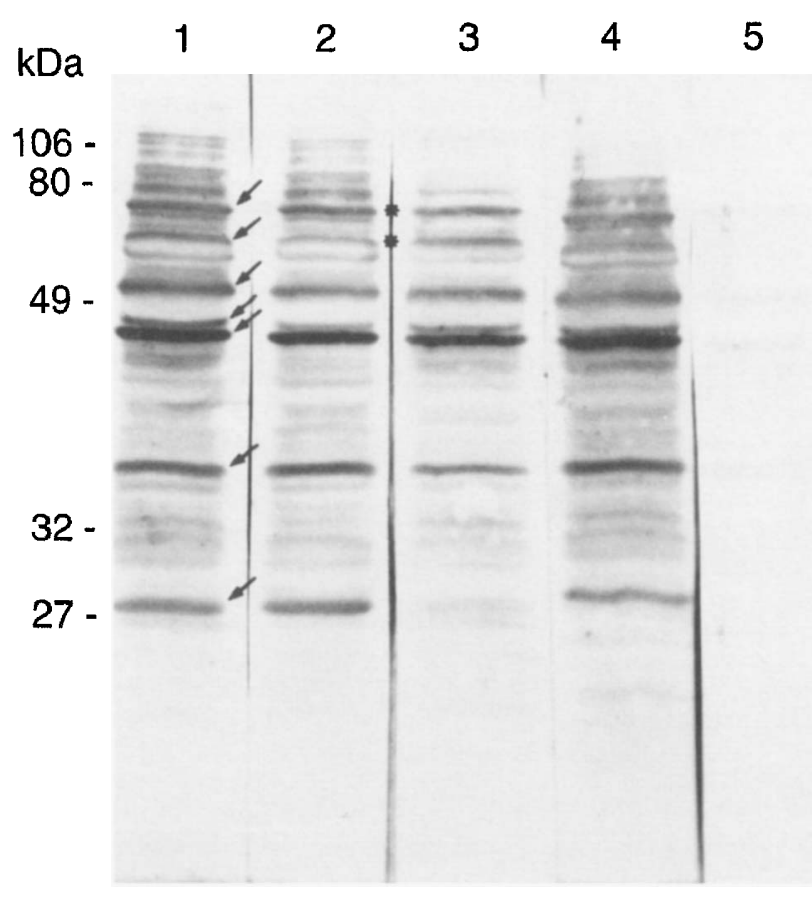

Fig. 4. Western blot analysis of sera from patients with rheumatic fever (RF) or mild streptococcal diseases (MSD). Total cell proteins from $S$. pyogenes (145/93) were separated on SDS-PAGE $10 \%$ gels and probed with human sera. Lanes: 1 and 2, MSD; 3 and 4, RF; 5, normal serum. Arrows indicate major immunogenic bands, asterisks indicate bands with the same mol.wt as GroEL and DnaK homologues and mol.wt standards are indicated on the left in $\mathrm{kDa}$.

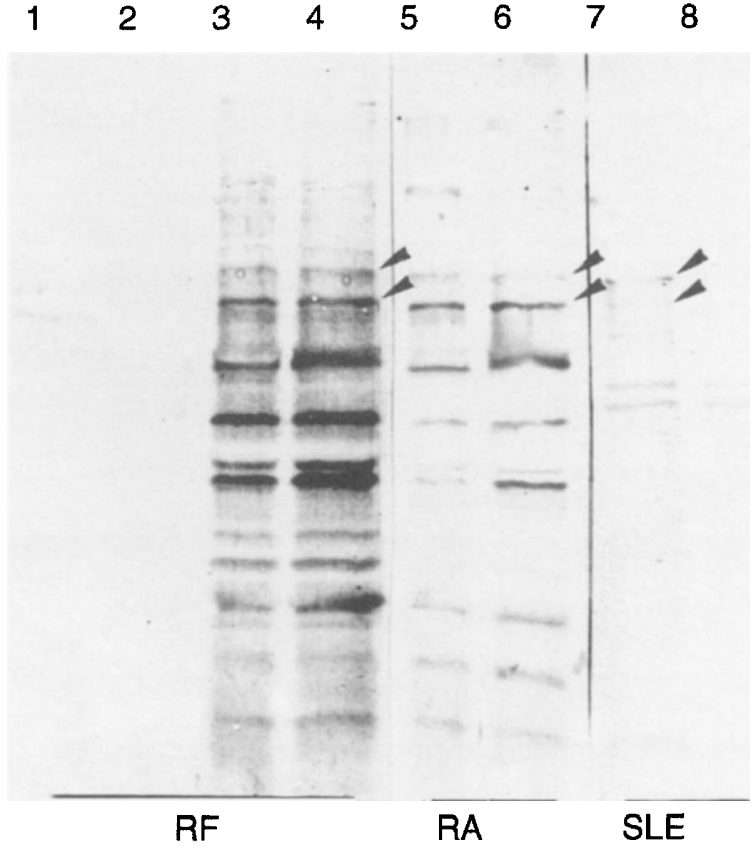

Fig. 5. Western blot analysis of sera from patients with rheumatic fever (RF), rheumatoid arthritis (RA) and systemic lupus erythematosus (SLE) against protein lysates of $E$. coli, $M$. tuberculosis and $S$. pyogenes. Lanes contain proteins from: 1, E. coli; 2, $M$. tuberculosis; $\mathbf{3}, \mathbf{5}, \mathbf{8}, S$. pyogenes non-heat-shocked cells; 4, 6, 7, S. pyogenes heat-shocked cells. Arrows indicate GroEL and DnaK proteins.

bands in $S$. mutans; these proteins also belonged to the DnaK and GroEL families. Eight HSPs were found in Staphylococcus aureus by two-dimensional electrophoresis when this micro-organism was subjected to heat shock at $46^{\circ} \mathrm{C}$ [11] and in Leuconostoc mesenteroides, cells subjected to heat shock, cold shock or ethanol treatment showed the presence of two major HSPs of 60 and $70 \mathrm{kDa}$ [12]. Two-dimensional analysis of $S$. pyogenes revealed an increase in the intensity of three spots at $42^{\circ} \mathrm{C}$, but only one isoform of each GroEL and DnaK protein was observed. In some bacteria, e.g., Borrelia burgdorferi [13], the presence of more than one isoform of these proteins has been demonstrated. Therefore, the possibility that additional members of HSP 60 and HSP 70 families exist in S. pyogenes which are not cross-reactive with the polyclonal antibodies used cannot be disregarded.

The induced $S$. pyogenes $65-\mathrm{kDa}$ protein also reacted with the MAb anti- $B$. pertussis HSP 63 , but failed to react with MAbs against HSP 65 of $M$. tuberculosis. Quinn et al. [8] showed in an immunoblot assay that the streptococcal GroEL failed to react with the mycobacterial HSP 65 polyclonal antibody, although it reacted with the Legionella HSP 60 antibody. These results suggest that these anti-mycobacterial antibodies were directed against epitopes not shared by $S$. pyogenes.

Many bacterial HSPs have been shown to be 
immunogenic proteins. Epitopes shared among immunodominant antigens of infectious agents may be important in the development of immunity against diverse pathogens [3]. It is currently thought that HSPs from bacteria are involved in the rheumatic diseases, as seen in RA [14]. It has been demonstrated that pre-treatment of rats with $M$. tuberculosis HSP 65 protected them from developing both $M$. tuberculosisinduced arthritis and streptococcal cell wall (SCW)induced arthritis [4].

The early phase of RF, characterised by polyarthritis and erythema marginatum [15], may represent pathogenic pathways similar to those found in RA. Several unanswered questions remain, despite many advances in the understanding of the pathogenesis of RF [15]. In 1990, Bahr and colleagues [5] examined the sera from 53 RF patients in an ELISA against members of the HSP 60 and HSP 70 families of E. coli, $M$. tuberculosis and human cells. They found that sera from these patients did not differ from normal control sera. In this study, Western blot analysis of $S$. pyogenes whole-cell proteins probed with human sera from patients with RF or with MSD demonstrated at least seven major immunogenic proteins. Two of these proteins corresponded in molecular mass to the $S$. pyogenes DnaK and GroEL homologues. Furthermore, it was observed that sera from patients with RA and SLE showed a specific reaction with $S$. pyogenes proteins and not with $E$. coli or $M$. tuberculosis proteins. The $75-$ and $65-\mathrm{kDa}$ heat-inducible proteins were present in the SLE and RA sera. Thus, antibodies to what appeared to be HSPs were present in sera from RF, RA and SLE patients. Autoantibodies against HSPs 65,70 and 90 have been detected in various rheumatic and autoimmune disorders, including SLE and RA [14] and these results may support the hypothesis of the involvement of HSPs in $S$. pyogenes infections and their sequelae.

The current state of knowledge indicates that some auto-immune disorders manifiest T-cell responses to HSPs, as do rats with adjuvant arthritis. The B-cell response to HSPs has been observed in many infectious and auto-immune diseases; however, the frequency of these antibodies varies amongst studies and is dependent upon the detection methods. Studies evaluating the sensitivity and specificity of these antibodies have not been described. Therefore, the humoral response against HSPs shoud be interpreted with caution.

In conclusion, this study demonstrated that $S$. pyogenes exposed to high temperatures shows increased production of two HSP homologues to DnaK and GroEL proteins and a reduction in general protein synthesis. The clinical significance of $S$. pyogenes HSPs in streptococcal infections is unknown, but antibodies against these proteins were observed in sera from patients with RF and MSD. Also, Quinn et al. [8] demonstrated that antibodies produced against myco- bacterial HSP can react with $S$. pyogenes M protein. It has been suggested that antibodies to $M$ protein may play a role in the pathogenesis of severe group $A$ streptococcal disease in general and of RA and RF [16]. Thus, the role of $S$. pyogenes HSPs in the pathogenesis of streptococcal diseases should also be considered.

This research was supported by PRONEX, CAPES, CNPq, FUJB, FAPERJ, FINEP and CEPG-UFRJ. We thank Dr Drusilla Burns (FDA, Maryland, USA); Dr T. Shinnick (Centers for Disease Control and Prevention, Atlanta, USA); Dr C. Georgopoulos (Center of Medical University, Geneva, Switzerland); and Dr D. R. Nelson (University of Rhode Island, USA) for kindly providing the MAbs against $B$. pertussis and $M$. tuberculosis (under the auspices of the World Health Organization), and the polyclonal antibodies against DnaK and GroEL, respectively. We are also grateful to Dr J. Kalil Filho (Instituto do Coração, USP, Brazil) and Dr Ana Aranha (Instituto Fernandes Figueiras, Brazil), for providing the human sera. We thank Dr A. Norton Hagler for revision of the English.

\section{References}

1. Kaplan EL. The resurgence of group A streptococcal infections and their sequelae. Eur J Clin Microbiol Infect Dis 1991; 10: 55-57.

2. Lindquist $\mathrm{S}$. The heat-shock response. Annu Rev Biochem 1986; 55: $1151-1191$.

3. Kaufmann SHE. Heat shock proteins and immune response Immunol Today 1990; 11: 129-136.

4. Van den Broek MF, Hogervorst EJM, Van Bruggen MCJ, Van Eden W, Van der Zee R, Van den Berg WB. Protection against streptococcal cell wall-induced arthritis by pretreatment with the $65-\mathrm{kD}$ mycobacterial heat shock protein. J Exp Med 1989 ; 170: $449-466$.

5. Bahr GM, Yousof AM, Majeed HAM et al. Agalactosyl IgG antibodies to heat shock proteins, and acute rheumatic fever. Ann Rheum Dis 1990; 49: 383-386.

6. Lehner T, Lavery E, Smith $R$, van der Zee $R$, Mizushima $Y$ Shinnick T. Association between the 65-kilodalton heat shock protein, Streptococcus sanguis, and the corresponding antibodies to Behcet's syndrome. Infect Immun 1991; 59: 1434-1441.

7. Jayaraman GC, Burne RA. DnaK expresssion in response to heat shock of Streptococcus mutans. FEMS Microbiol Let 1995; 131: 255-261.

8. Quinn A, Shinnick TM, Cunningham MW. Anti-HSP65 antibodies recognize $\mathrm{M}$ proteins of group $\mathrm{A}$ streptococci. Infect Immun 1996; 64: 818-824.

9. Ausubel FM, Brent R, Kingston RE, Moore DD, Seidman JG Smith K. In: Current protocols in molecular biology, vol. 2 , Ch. 10. Wiley Interscience. 1994-1997: 10.0.5-10.20.13.

10. Froude J, Gibofsky A, Buskirk DR, Khanna A, Zabriskie JB Cross-reactivity between Streptococcus and human tissue: a model of molecular mimicry and autoimmunity. Curr Top Microbiol Immunol 1989; 145: 5-26.

11. Ohta T, Honda K, Kuroda M. Saito K, Hayashi H. Molecular characterization of the gene operon of heat shock protein HSP60 and HSP10 in methicillin-resistant Staphylococcus aureus. Biochem Biophys Res Commun 1993; 193: 730-737.

12. Salotra P, Singh DK, Seal KP, Krishna N, Jaffe H, Bhatnagar $\mathrm{R}$. Expression of DnaK and GroEL homologs in Leuconostoc mesenteroides in response to heat shock, cold shock or chemical stress. FEMS Microbiol Lett 1995; 131: 57-62.

13. Carreiro MM. Laux DC, Nelson DR. Characterization of the heat shock response and identification of heat shock protein antigens of Borrelia burgdorferi. Infect Immun 1990; 58 2186-2191

14. Kiessling R, Gronberg A, Ivanyi $\mathbf{J}$ et al. Role of hsp60 during autoimmune and bacterial inflammation. Immunol Rev 1994; 121: $91-111$.

15. Smiley JD, Hoffman WL. The role of infections in the rheumatic diseases: molecular mimicry between bacterial and human stress proteins? Am J Med Sci 1991; 301: 138-149.

16. Baird RW, Bronze MS, Werner K, Hill HR, Veasy LG, Dale JB. Epitopes of group A streptococcal M protein shared with antigens of articular cartilage and synovium. J Immunol 1991; 146: $3132-3137$. 